Résumés des conférences et travaux

\title{
Histoire des institutions européennes
}

Jean-Pierre Machelon

\section{OpenEdition \\ Journals}

Édition électronique

URL : https://journals.openedition.org/ashp/478

DOI : 10.4000/ashp.478

ISSN : 1969-6310

Éditeur

Publications de l'École Pratique des Hautes Études

\section{Édition imprimée}

Date de publication : 1 octobre 2008

Pagination : 284-285

ISSN : 0766-0677

\section{Référence électronique}

Jean-Pierre Machelon, « Histoire des institutions européennes », Annuaire de l'École pratique des hautes études (EPHE), Section des sciences historiques et philologiques [En ligne], 139 | 2008, mis en ligne le 26 novembre 2008, consulté le 12 juillet 2021. URL : http://journals.openedition.org/ashp/478 ; DOI https://doi.org/10.4000/ashp.478 


\title{
HISTOIRE DES INSTITUTIONS EUROPÉENNES
}

\author{
Directeur d'études : M. Jean-Pierre MACHELON
}

Programme de l'année 2006-2007 : I. Cultures constitutionnelles et institutions représentatives dans les grands États européens. - II. Prosopographie du personnel politique et administratif français à l'époque contemporaine (suite).

L'analyse comparée des cultures constitutionnelles et de la vie parlementaire en Europe, commencée en 2002 et poursuivie depuis lors, s'est orientée au cours de l'année universitaire 2006-2007 autour de deux grands chapitres, les régimes électoraux et les transitions constitutionnelles. Les évolutions divergentes de la France et de la Grande-Bretagne en matière électorale depuis le XVIII ${ }^{\mathrm{e}}$ siècle ont alimenté une première série de réflexions et de discussions. Le directeur d'études a présenté ensuite, du point de vue théorique et historique, la question de l'abrogation des constitutions, dans le prolongement des explications antérieurement données sur leur établissement et leur révision (voir le rapport précédent). L'intérêt de la conférence a été dirigé tout particulièrement, exemples à l'appui, vers une typologie des coups d'État (pratiqués par des autorités en place) et des révolutions (provoquées de l'extérieur). Chemin faisant, le cas du Seize Mai a été examiné en détail, tandis qu'étaient scrutés certains personnages relativement mal connus de l'histoire politique française, comme Jules Grévy. La problématique des gouvernements provisoires, de droit et de fait, a aussi été abordée, dans ses dimensions juridiques (les changements de régime politique, la continuité de l'État) et de philosophie politique (les querelles de légitimité).

Comme annoncé, l'attention de la conférence a par ailleurs été appelée sur la méthode prosopographique, ses techniques et ses applications à l'histoire contemporaine, avec le concours très diligent de $\mathrm{M}$. François Naud, ingénieur d'études à la Section et auteur, il y a quelques années, d'une vaste recherche sur les parlementaires de Loire-Inférieure qui devrait être publiée prochainement. Divers travaux d'érudition illustrant l'intérêt de cette approche, et déjà évoqués dans les rapports précédents, ont continué d'être examinés et commentés en séance. Deux d'entre eux viennent d'être achevés, le substantiel ouvrage (en deux volumes) de M. Jean-Marc Valentin sur les cinquante-sept parlementaires élus dans les départements d'Algérie sous la Troisième République, qui a donné lieu le 20 juin à la soutenance d'un mémoire pour le diplôme de l'École, et la somme que le professeur Nicole Herrmann-Mascard a consacrée aux deux premières séries de nominations à la Cour des comptes, en 1807-1808 (cent quatre au total). À l'heure du deuxième centenaire de la fondation de la Cour par Napoléon, ce Dictionnaire biographique, déjà sous presse, vient fort opportunément; et, de même que les notices biographiques des élus d'Algérie instruisent avec une profondeur surprenante sur la vie politique et parlementaire de leur temps, il montre avec quelle sûreté les méthodes et techniques de la prosopographie, pourtant réputées aus- 
tères, peuvent faire revivre le passé, et en l'occurrence la jeunesse, d'une institution administrative encore incomplètement explorée.

D'autres recherches se poursuivent, ou sont entreprises, sur le personnel politique et administratif français. En généalogiste confirmé, M. Jean-Marc Valentin épluche désormais les dossiers des maires de la commune de Vanves (Hauts-de-Seine). M. Roger Levêque, après avoir publié (sur Internet) son étude sur le Cercle national des chemins de fer, s'intéresse plus spécialement aux hommes politiques qu'il a répertoriés à cette occasion. Il a ainsi présenté la figure assez singulière du sénateur inamovible Léon Lalanne, ancien directeur de l'École nationale des ponts et chaussées et de la Compagnie des omnibus de Paris, plus connu des ingénieurs (praticiens de « l'épure Lalanne ») que des spécialistes d'histoire politique. M. Naud, pour sa part, a rendu compte du travail fort approfondi qu'il mène depuis plusieurs années sur les représentants, députés et sénateurs élus dans le département du Tarn-et-Garonne sous la Troisième République (1871-1940), et, plus généralement, sur les grandes personnalités politiques du département (à commencer par Léon de Maleville, ministre de l'Intérieur en 1849). Ses prometteuses investigations laissent espérer à terme relativement rapproché des mises au point d'importance, notamment sur Charles de Freycinet, qui, en dépit du halo de grisaille dont l'a entouré l'historiographie traditionnelle, demeure l'un des principaux personnages consulaires de la République opportuniste.

Sur un terrain voisin, la conférence a marqué de l'intérêt pour la publication (enfin) intégrale, dont M. Naud a parallèlement entrepris la préparation, des mémoires politiques de Bernard Lavergne, député, puis sénateur du Tarn, et confident du président Grévy. Les dépouillements pratiqués par M. Pierre Coget en vue de sa thèse de doctorat en histoire sur l'esprit public dans le département de l'Aisne dans les débuts de la Troisième République ont également nourri la réflexion collective. L'auditoire, toujours attentif à l'histoire politique, est enfin, cette année encore, resté associé à l'examen du journal inédit du sénateur Charles François Saint Maur (1869-1949), que sa famille est disposée à publier, au moins partiellement (voir les rapports précédents). 